Original Research Article

\title{
Quality of life in children with bronchial asthma
}

\author{
Wander $A^{1}$, Bhargava $S^{2}$, Pooni P.A $A^{3}$, Kakkar $S^{4}$, Arora $K^{5}$ \\ ${ }^{1}$ Dr. Arvinder Wander, Senior Resident, Department of Pediatrics, AIIMS, New Delhi, ${ }^{2}$ Dr. Siddharth Bhargava, \\ Assistant Professor, ${ }^{3}$ Dr. Puneet A Pooni, Professor and Head, ${ }^{4}$ Dr. Shruti Kakkar, Assistant Professor, \\ ${ }^{5}$ Dr. Kamaldeep Arora, Assistant Professor, above authors are affiliated with Department of Pediatrics, \\ Dayanand Medical College and Hospital, Ludhiana, Punjab, India.
}

Address for Correspondence: Dr Siddharth Bhargava, Assistant Professor, Department of Pediatrics, Dayanand Medical College and Hospital, Ludhiana, Punjab. Email: siddharthb27@gmail.com

\begin{abstract}
Introduction: Bronchial asthma is one of the most common childhood diseases. It imposes significant burden on children's health related quality of life despite the availability of effective and safe treatment. So, this study was conducted to assess the quality of life (QOL) in children with bronchial asthma and to study the impact of various clinical and socio-demographic factors on their QOL. Methods: Observational, hospital based study conducted in Pediatric chest clinic of a tertiary care teaching Hospital on children between 7-17 years of age, newly or previously diagnosed with bronchial asthma over a period of one year. Using the Pediatric Asthma Quality of Life Questionnaire (Standardized), (PAQLQ(S)) the quality of life was assessed in relation to clinical and socio-demographic data among newly diagnosed and follow-up cases of asthma. Results: Of the 90 children enrolled, 20 were newly diagnosed and 70 were follow up cases with male female ratio of 2.1: 1 . Children reported more impairment in PAQLQ(S) scores if the onset of symptoms was before one year of age, in those with frequent exacerbations, poor treatment compliance, poorly controlled symptoms and Children with history of school absenteeism. The mean PAQLQ(S) score was lowest in emotional function among newly diagnosed and follow up cases. Statistically significant difference was observed between PAQLQ(S) scores of controlled, partly controlled and uncontrolled cases of asthma. Conclusion: Although children improved clinically with treatment, asthma had a significant impact on emotional status of the children.
\end{abstract}

Keywords: Limitation of activity, Asthma severity, Emotional function, Pediatric Asthma Quality of Life Questionnaire (Standardized), PAQLQ(S), School absenteeism

\section{Introduction}

Bronchial asthma is one of the most common childhood diseases and is a leading cause of emergency care requirements as well as a cause for considerable morbidity, disability and occasional mortality at all ages.

While managing a patient with any disease, conventional clinical measures usually provide valuable information about the status of the affected organ system, but they rarely capture the functional impairments (physical, emotional, and social) that are important to children in their everyday lives. There is now clear evidence that the

Manuscript received: $2^{\text {nd }}$ June 2017

Reviewed: $11^{\text {th }}$ June 2017

Author Corrected: $20^{\text {th }}$ June 2017

Accepted for Publication: $28^{\text {th }}$ June 2017 clinical indices only weakly correlate with how the child is feeling and how the child functions in everyday situations. To obtain a complete picture of a child's health status, both conventional clinical indices and the child's Health related quality of life (HRQL) have to be measured. In addition, investigators have shown that parents may not perceive their child's asthma related quality of life accurately [1].

Very few studies have been conducted in India to measure quality of life in children suffering from asthma. So this study was initiated to know the quality of life in children suffering from asthma, their problems and areas in which they lag behind their colleagues. 


\section{Methods}

Design:Prospective, observational study conducted over one year, $1^{\text {st }}$ April 2013 to $31^{\text {st }}$ March 2014.

Setting: Pediatric Chest Clinic in the Department of Pediatrics, Dayanand Medical College and Hospital, Ludhiana.

Inclusion criteria: Children in the age group of 717 years, newly or previously diagnosed with bronchial asthma.

Exclusion criteria: Patients who did not give consent for the study, children with other coexisting chronic diseases, developmental retardation or inability to answer PAQLQ(S) questionnaire.

Diagnosis and assessment of severity of bronchial asthma in the current study was done as per "Asthma by Consensus (ABC)" guidelines of Indian Academy of Pediatrics (IAP).[2] Grades of severity of asthma at initial diagnosis were categorized into intermittent, mild persistent, moderate persistent and severe persistent on the basis of day time and night time symptoms and those who were already on treatment were categorized into controlled, partly controlled and uncontrolled as per day time symptoms, limitations of activities and nocturnal symptoms.

The study was approved by the Institutional Ethics Committee and informed consent was obtained from caregivers of the enrolled children. The enrolled Children were given Pediatric Asthma Quality of Life Questionnaire (Standardized), PAQLQ(S). Permission was also taken for using PAQLQ(S) from Elizabeth Juniper on behalf of QOL Technologist Ltd. through the institution.

The PAQLQ(S) has been developed to measure the functional (physical, emotional, occupational and social) problems that are most troublesome to children of 7-17 years with asthma.[3] PAQLQ(S) has 23 questions in three domains (symptoms, activity limitations and emotional function). Children were asked to recall their experiences during the previous week and to respond to each question on a 7-point scale ( $7=$ no impairment, $1=$ severe impairment). Hence, a low score meant poor 'Health related quality of life'(HRQL). Individual questions were equally weighted. The overall PAQLQ score was calculated as the mean of the responses to each of the 23 questions. The resultant overall score was between 1 and 7 . The individual domains were analyzed in exactly the same way. Two types of questionnaires were used - self administered and interviewer administered. Children of age $\leq 10$ year were given interviewer administered questionnaire and children of age $>$ 10 years were provided self administered questionnaire. Individual variables evaluated included clinical and socio-demographic characteristics. Association between mean PAQLQ (S) scores and individual variables was evaluated.

Symptom analysis (cough, wheeze etc) was done and various factors like age of onset of symptoms, frequency of day time and night time symptoms were asked. Details such as age at which asthma was first diagnosed, history of exacerbations and their predisposing factors, number of OPD visits, admissions and whether missing school because of asthma symptoms were noted. Treatment details including compliance to treatment were recorded. In case of non adherence, factors responsible for non adherence were noted down.

All the factors mentioned above were considered for comparing quality of life in children with bronchial asthma. With respect to overall mean score as well as individual domain score mean of PAQLQ(S) comparison for quality of life was done between different grades of severity of asthma. Two groups were considered for comparison. First was newly diagnosed cases (those who presented first time in OPD) and second group comprised of follow up cases (those who were already on treatment). No controls were taken for the study.

Statistical analysis- Results were expressed as mean \pm SD (Standard deviation) or number percentage. Comparison of different parameters between groups was performed using unpaired ttest and for more than two groups using ANOVA. Comparison between categorical data was performed using chi-square test and data was considered significantly if $\mathrm{P}$ value $\leq 0.05$. Statistical analysis was performed with aid of SPSS version 17.0.

\section{Results}

A total of 90 children were enrolled in the study, out of which 20 children were newly diagnosed and 
70 were follow up cases with male female ratio of 2.1: 1 . Maximum children were in the age group of 7 to 12 years $(n=67,74.4 \%)$ followed by 13 to 17 years $(n=23,25.6 \%)$. Of these, 52 children $(57.8 \%)$ were given interviewer administered and 38 children $(42.2 \%)$ were given self administered PAQLQ (S) questionnaire. The overall and individual domain PAQLQ scores were comparable in the age ranges of 7 to 12 years (Mean $\pm 2 \mathrm{SD}=$ $4.92 \pm 0.87)$ and 13 to 17 years $(5.02 \pm 0.80) ;(\mathrm{P}=$ $0.636)$.

Children were also categorized into different age groups according to the age of onset of symptoms and its relationship to PAQLQ was studied. Minimum mean score was recorded in those with onset of symptoms < 1year of age (overall mean score 4.19). There was statistically significant adverse impact on quality of life in activity limitation domain $(\mathrm{p}$ value $=0.039)$ and emotional function domain $(\mathrm{p}$ value $=0.007)$ in children who had onset of symptoms during infancy. Age of onset of symptoms $<1$ year was associated with maximum impairment of quality of life (activity limitation score $=4.03$, symptom score $=4.23$, emotional function score $=3.60$ ) . Emotional function was the most impaired domain in all the age groups that were studied.

Children who had asthma exacerbations had less overall mean score (4.11) as compared to those who did not have exacerbations (overall score mean $=5.08)$ which was statistically significant $(\mathrm{P}$ $=0.001)$. Children who had asthma exacerbations reported more impairment in the emotional function domain $(3.83 \pm 1.11)$ than in symptoms $(3.90 \pm 1.05)$ and activity limitations $(4.24 \pm 1.02)$.

About 31 Children (34\%) gave history of missing school due to Asthma symptoms. Out of these, 17 $(54.8 \%)$ children belonged to moderate persistent category and $7(22.6 \%)$ children each were from mild persistent and intermittent category respectively. Children who had history of missing school because of asthma had an overall mean score of 4.63, compared to a score of 5.11 in those who did not miss school ( $\mathrm{P}=0.008)$.

These Children reported significantly more impairment in the domains of activity limitations than in symptoms and emotional function $(\mathrm{P}=$ 0.001). The number of OPD visits and frequency of asthma related admissions did not impact the PAQLQ score.

Out of the 20 newly diagnosed cases $10(50 \%)$ were mild persistent, 7 (35\%) were intermittent and $3(15 \%)$ were moderate persistent. None of the patients had severe persistent asthma. Overall score mean was highest in intermittent category (overall score mean $=5.58$, activity limitations $=5.77$, symptoms $=5.41$, emotional function $=4.95$ ) and was minimum in moderate persistent category (overall score mean $=3.87$, activity limitations $=$ 4.20 , symptoms $=3.73$, emotional function $=3.25$ ) . Among all categories of severity most impaired domain was emotional function $(\mathrm{P}=.011)$, followed by symptoms $(\mathrm{P}=.017)$ and least impaired was activity limitations( $\mathrm{P}=.007)$.

Out of the 70 follow up cases, the overall score mean and individual domain score mean was highest in controlled, followed by partly controlled and least in uncontrolled category (Overall score mean $\mathrm{P}=0.001$, activity limitations $\mathrm{P}=0.001$, symptoms $\mathrm{P}=0.005$, emotional function $\mathrm{P}=$ $0.003)$.The most affected domain was emotional function followed by symptoms and least affected was activity limitation. Amongst the children who were categorized as Intermittent at initial diagnoses $83.3 \%$ were controlled and $16.7 \%$ were partly controlled on follow up. None of them was in uncontrolled category. In the mild persistent category, $65.4 \%$ were controlled, $30.8 \%$ were partly control and $3.8 \%$ were uncontrolled. Maximum number of poorly controlled patients (uncontrolled $43.8 \%$ and partly controlled 40.6\%) were seen in moderate persistent category.

With regard to treatment compliance, $49 \%$ children were adherent to treatment. Their overall score mean as well as individual score mean was higher than those who were not adherent to treatment (Overall score mean $\mathrm{P}<0.001$, activity limitations $\mathrm{P}=0.001$, symptoms $\mathrm{P}=0.001$, emotional function $\mathrm{P}<0.001)$. The maximum score was observed in activity limitations, which signifies that those who were adherent had maximum improvement in activity scores and least in emotional function.

\section{Discussion}

This observational study was aimed at assessing the factors affecting the quality of life in children suffering from bronchial asthma. PAQLQ(S) 
[Pediatric asthma quality of life questionnaire standardized] developed by Juniper et al. formed the basis of the study [3,4]. Asthma related Quality of Life was maximally affected in children below one year, those who had frequent exacerbations, poor treatment compliance and poorly controlled symptoms.

In our study, PAQLQ (s) scores of all 3 domains were lowest in children who developed symptoms before one year of age. It could probably be because bronchiolitis and other lower respiratory tract infections which are more common in infancy are known to be an antecedent for subsequent wheezing and asthma during childhood. The same was observed in another study [5]. Severe respiratory ailments during infancy might predispose infants to malnutrition during a crucial phase of growth and hence adversely affect the subsequent quality of life during childhood.

In the current study, children who had exacerbations of asthma had significantly less overall mean score as compared to those who did not have exacerbations. Children who had asthma exacerbations reported maximal impact on emotional functional domains and least effect on activity limitations. The reason could probably be that hospitalization of children because of asthma exacerbations and IV medications given during hospital stay may cause adverse emotional impact on children. This result is similar to another study [6]. They reported a significant decrease $(\mathrm{P}<.001)$ in Mini-AQLQ domain scores with increasing severity of asthma exacerbation. Another fact noted in our study was that 31 children (34\%) had history of missing school because of asthma symptoms.

These children had significantly lesser mean scores compared to those who did not miss school and the maximum impact was on activity limitation. Similarly, a western study evaluated the impact of uncontrolled asthma on school absenteeism and health-related quality of life (HRQL) [7].

They concluded that $70 \%$ children with uncontrolled asthma versus $45 \%$ with controlled asthma missed school, with a median of 6 days versus 4 days missed respectively (during the study period). The PAQLQ score in our study was not affected by the number of OPD visits or frequency of asthma related admissions.
Our study also demonstrated that as the grade of severity of asthma increased, the quality of life got more impaired both in newly diagnosed as well as follow up cases. The impairment was maximum in the emotional domain. Moreover, patients with severe asthma reported more limitation in their activity score as well, a finding that is similar to results published from previous studies conducted in Serbia[8] and Iran [9]. Yet another study found that the overall HRQL score was lower in children with severe asthma compared to those subjects in whom asthma was controlled (5.4 vs. 6.7, $\mathrm{p}<0.001$ ) [10]. According to the Serbian study, impairment in the activity limitation domain is explained by the patient's concerns about exacerbating their asthma.[8] It is logical that these children would avoid any activities that could trigger an asthma attack. Similarly, in our study children with moderate persistent asthma had more activity limitation as compared to mild persistent and intermittent categories ( $\mathrm{P}<0.007)$. Similarly, another Indian study concluded that mild to moderate QOL impairment occurred in activity domain (mean score 5.17) and emotional domain (mean score 5.00) [11].

In the current study, among intermittent, mild persistent and moderate persistent asthma cases most impaired domain was emotional function, followed by symptoms and least impaired was activity limitation. However, a study done by Farnik and Coworkers showed different results from our study [12]. They concluded that in the children studied, the most impaired domain was activity limitation.

The same trend was observed in patients who were already on follow up, with the lowest PAQLQ scores in uncontrolled patients and highest scores in the controlled group. In our study mean score among follow up cases was maximum in activity limitation domain in all three categories (controlled, partially controlled and uncontrolled cases) and mean score was minimum in emotional function domain in all categories.

It was also observed that overall improvement in children's HRQOL occurred with treatment. However, least statistically significant change occurred in emotional function domain of PAQLQ(S) even after improvement in asthma symptoms. 
Original Research Article

Similarly, when follow up children of each category were individually compared for HRQL scores in relation to their initial severity at presentation, it revealed maximum improvement in activity limitation followed by symptoms perception and least in emotional function. It indicates that although significant improvement was achieved in the activity level and symptoms, these children did not recover emotionally from the impact of the disease despite treatment. Our study results are similar to another Indian study [13].

Statistically significant improvement in the activity limitation and the symptom category of the mini PAQLQ $(\mathrm{P}<0.001)$ after treatment was noted. There was also a significant change in the mean grand total scores showing an overall improvement in the child's condition with medical intervention. However, no statistically significant change was noted in the emotional domain of the mini PAQLQ even after medical intervention.

Another fact brought out in the study was that adherence to treatment was associated with improved HRQOL both in the overall score and individual domains, which was also demonstrated by studies done in Brazil [14] and Egypt [15] respectively.

\section{Conclusion}

Thus, the study concluded that emotional function domain was most impaired because of asthma . This could probably be because of limitation of sports and other daily activities and because asthmatic children tend to miss school. School absenteeism leads to poor academic performance causing low self esteem.

Frustration builds-up due to inability to perform daily activities, in addition to dietary restrictions imposed by the parents due to food fads. All these factors add on to emotional deprivation which causes a major impact on quality of life in children. It stresses the importance of providing psychological support and counseling in the long term management of asthma.

Abbreviations: HRQL, PAQLQ(S), ABC, IAP, Mini-AQLQ, QOL

Funding: Nil, Conflict of interest: None initiated, Perission from IRB: Yes

\section{References}

1. Guyatt GH, Juniper EF, Griffith LE, Feeny DH, Ferrie PJ. Children and adult perceptions of childhood asthma. Pediatrics. 1997 Feb; 99(2): 165-8.

2. Khubchandani R, Gajendragadkar A, Singh V, Kabra S, Sethi GR, Reddy S et al. Asthma by consensus. consensus guidelines for the diagnosis and management of asthma in children. IAP Respiratory Chapter. 2013. p. 1-3.

3. Juniper EF, Guyatt GH, Feeny DH, Ferrie PJ, Griffith LE, Townsend M. Measuring quality of life in children with asthma. Qual Life Res. 1996 Feb; 5 (1):35-46.

4. Juniper EF, Guyatt GH, Willan A, Griffith LE. Determining a minimal important change in a disease-specific Quality of Life Questionnaire. J Clin Epidemiol. 1994; 47:81-7. doi: http:// dx.doi. org/ $10 . \quad 1016 / 0895-4356 \quad$ (94) 900 36-1.

5. Beigelman A, Bacharier LB. The role of early life viral bronchiolitis in the inception of asthma. Curr Opin Allergy Clin Immunol. 2013 Apr; 13(2):211-6. doi: 10. 1097/ACI. 0b013e 32835 eb6ef.

6. Luskin AT, Chipps BE, Rasouliyan L, Miller DP, Haselkorn T, Dorenbaum A. Impact of asthma exacerbations and asthma triggers on asthmarelated quality of life in patients with severe or difficult-to-treat asthma. J Allergy Clin Immunol Pract. 2014 Sep-Oct;2(5):544-52.e1-2. doi: 10.1016 /j.jaip.2014.02.011. Epub 2014 Jul 3.

7. Dean BB, Calimlim BM, Kindermann SL, Khandker RK, Tinkelman D. The impact of uncontrolled asthma on absenteeism and healthrelated quality of life. J Asthma. 2009 Nov;46(9):861-6. doi: 10.3109/02770900 90318 4237.

8. Cerović S, Zivković Z, Milenković B, Stojanović JJ, Bajec AO, Vukaŝinović Z, Veković V. The Serbian version of the pediatric asthma quality of life questionnaire in daily practice. J Asthma. 2009 Nov; 46 (9):936-9. doi: 10.3109/0277090090 326 5812. 
9. Zandieh F, Moin M, Movahedi M. Assessment of quality of life in Iranian asthmatic children, young adults and their caregivers. Iran J Allergy Asthma Immunol. 2006 Jun;5(2):79-83.

10. Nordlund B. Konradsen JR, Pedroletti C, Kull I, Heldin, G. The clinical benefit of evaluating health-related quality of life in children with problematic severe asthma. Acta Paediatr. 2011;100:1454-60. doi: 10.1111/j.1651-2227.2011. 02359.x.

11. Chand N, Singh MS, Brar P, Bhatia AS, Singh J. Measuring quality of life in young children with asthma in Amritsar (India) free to view. Chest. 2004; 126. doi:10.1378/chest. 126.4_Meeting Abstracts.762S.

12. Farnik M, Pierzchała W, Brożek G, Zejda JE, Skrzypek M. Quality of life protocol in the early asthma diagnosis in children. Pediatr Pulmonol. 2010 Nov; 45 (11): 1095-102.doi: 10.1002/ppul. 21293.

13. Nair S, Nair S, Sundaram KR. A prospective study to assess the quality of life in children with asthma using the pediatric asthma quality of life questionnaire. Indian J Allergy Asthma Immunol 2014;28:13-8

14. De souza PG, Anna CCS, de Fatima M. Quality of life in childimensions ren with asthma in Rio de Janerio, Brazil. Rev Paul Pediatr. 2011; 29 (4): 544-8.

15. Al-Gewely MS, El-Hosseiny M, Abou Elezz NF, El-Ghoneimy DH, Hassan AM. Health-related quality of life in childhood bronchial asthma. Egypt J Pediatr Allergy Immunol. 2013; 11 (2): 83-93.

\section{How to cite this article?}

Wander A, Bhargava S, Pooni P.A, Kakkar S, Arora K. Quality of life in children with bronchial asthma. J PediatrRes.2017;4(06):382-387.doi:10.17511/ijpr.2017.i06.06. 